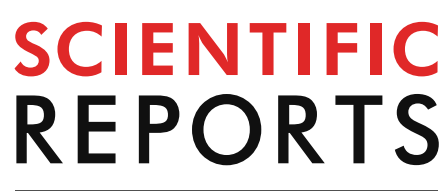

natureresearch

Check for updates

\title{
One-step fabrication
}

of carbonaceous adsorbent

from corncob for enhancing adsorption capability of methylene blue removal

\author{
Youming Wang ${ }^{1,2}$, Yulong Zhou ${ }^{1}$, Guojing Jiang ${ }^{1}$, Peirong Chen ${ }^{1 \bowtie}$ \& Zhen Chen ${ }^{1 \bowtie}$ \\ A novel and simple method was described for preparation of carbonaceous adsorbent (CA) from \\ corncob under phosphoric acid conditions. The method succeeded to introduce oxygen-containing \\ groups onto the product surface through hydrothermal carbonization (HTC) at low temperature of \\ $160^{\circ} \mathrm{C}$. Adsorption of methylene blue (MB) was studied systematically through the effect of $\mathrm{pH}$, \\ contact time and initial dye concentrations. The MB adsorption kinetics and isotherms experiments \\ showed that Langmuir model and pseudo-second-order model could better describe the adsorption \\ behavior, with a maximum adsorption capacity of MB was $140.25 \mathrm{mg} / \mathrm{g}$. The high adsorption capacity \\ could be ascribed to the presence of surface oxygen-containing functional groups and pore channels. \\ In conclusion, it could be a potential adsorbent in the removal of methylene blue from wastewater.
}

The presence of dyes in the wastewater can cause various detriment effects on human health and living organisms due to their not biodegradable and become a major environmental concern problem. These dyes are introduced in the freshwater from many industries, including cosmetics, leather, textile, paper, printing and dyeing industries $^{1-8}$. Methylene blue (MB) is one of the most typical dye pollutants in aqueous systems ${ }^{9}$. Until now, various techniques such as photochemical oxidation, reverse osmosis, membrane filtration, adsorption and ozonation have been developed for the purification of organic contaminants from aqueous solutions ${ }^{10-18}$. Among these techniques, adsorption is regarded as a superior technique for treating wastewater considering its process simplicity, nontoxic and inexpensive. In particular, tremendous attention has been attracted to the study of different types of biomass-derived adsorbents removing organic pollutants in waterways ${ }^{19-25}$.

According to a recent China's National Bureau of Statistics report, the Chinese annual yield of corn in 2017 was more than 21.5 million tons. The radio between corn gain and corncob may be about 100:18 ${ }^{26}$, rough estimate 3.8 million tons of corncobs could be generated in China every year. Corncob is a sort of environment friendly and renewable resource, widely existing in biomass. Currently, most of the corncobs are burned as low-grade fuels and not fully utilized, which cause both environmental pollution and natural resources waste. Therefore, reasonable and harmless utilization of corncob is important to change waste into valuables.

However, to date, the most widely biomass-derived adsorbents were prepared under the most demanding conditions with high pressure and high temperature ${ }^{27-29}$. In addition, widespread application is seriously restricted because of the relatively poor capability ${ }^{30}$. Therefore, chemical modification method is widely used presently to enhance their capabilities of biochar by introduction of oxygen-containing groups ${ }^{31-35}$. These oxygen-containing groups on the surface serve as adsorption sites for organic pollutants in solution. For example, Xu et al. reported that citric acid-promoted water hyacinth (Eichornia crassipes) was an efficient method for enhancing the adsorption capability of biochar for $\mathrm{MB}^{36}$. Rhamnolipid was employed to enhance the adsorption capability of biochar for removal of $\mathrm{MB}^{37}$. However, there have been few reports that phosphorylated modification at low temperature is investigated for improving adsorption capability of biochar in wastewater treatment.

${ }^{1}$ Department of Applied Chemistry, School of Natural Science, Anhui Agricultural University, Hefei 230036, Anhui, China. ${ }^{2}$ Key Laboratory of Biomass and Energy of Education, Department of Anhui Province, Anhui Agricultural University, Hefei 230036, China.『email: chenpeirong@ahau.edu.cn; zchen@ahau.edu.cn 
As one of most frequently used agents for chemical modifications, phosphoric acid is preferred recently for environmental and production costs. The phosphoric acid has played a vital role in the HTC process including the degradation of biomass and the formation of oxygen-containing surface functional groups. Thus, the main purpose of this research was to develop an effective modification method for preparing an alternative corncobderived adsorbent with $\mathrm{H}_{3} \mathrm{PO}_{4}$ at low temperature. These works help not only to improve adsorption capability of biochar but also greatly reduce the preparation temperature. In addition, we aim to characterize the properties of as-prepared adsorbent and study their sorption behaviors for MB.

\section{Methods}

Materials. Corncob used in this study was obtained from the a farm around Fuyang City, Anhui Province of China. Before processing, the corncob was washed by water, dried at $105^{\circ} \mathrm{C}$ for $24 \mathrm{~h}$ and smashed to pass through a $0.15 \mathrm{~mm}$ (100 mesh) sieve. Methylene blue (MB) was purchased from Sinopharm in Beijing, All chemicals were of analytical grades from the Shantou Xilong Chemical Factory, China.

Preparation of the corncob-derived adsorbent. The corncob powder $(5 \mathrm{~g})$ was added to $40 \mathrm{~mL}$ distilled water with a certain amount of phosphoric acid $(5 \mathrm{~mL})$ in a $100 \mathrm{~mL}$ Telon-lined reactor, then sonicated for $1 \mathrm{~h}$. The resulting mixture was heated to desired temperature for $10 \mathrm{~h}$ in the oven. After cooling, the sample was washed with distilled water, and then obtained by drying at $85^{\circ} \mathrm{C}$ over night.

Characterization techniques. The microstructure and functional groups of the samples was studied by the X-ray diffraction (XRD), Brunauer-Emmet-Teller (BET) and infrared spectroscopy (IR). Analyses of the morphology of the sample were conducted by a scanning electron microscope (SEM), Hitachi S-4800. The MB concentration was analyzed by using a UV-Vis spectrophotometer.

Adsorption experiments. All adsorption experiments were carried out in $50 \mathrm{~mL}$ polypropylene (PP) centrifuge tubes. With a procedure, the effect of initial $\mathrm{pH}$, contact time and initial $\mathrm{MB}$ concentrations on the adsorption of $\mathrm{MB}$ were examined in a series of experiments. Analytical simples were taken from the mixture solution at predetermined time intervals during the adsorption. The content of MB in the PP centrifuge tubes was determined by means of UV spectrophotometer.

For tests on the adsorption isotherm, the adsorbent concentration of $1 \mathrm{~g} / \mathrm{L}$ and the $\mathrm{MB}$ concentration varied from 5 to $300 \mathrm{mg} / \mathrm{L}$ under constant shaking on a rotary shaker at room temperature for $8 \mathrm{~h}$.

Desorption studies. In the experiments, adding a certain amount of the MB-adsorbed CA powder to $50 \mathrm{~mL}$ of $0.1 \mathrm{M} \mathrm{HCl}$ solution and stirring continuously for $120 \mathrm{~min}$ at ambient temperature, and then the MBdesorbed CA powders were filtered from the solution. After regeneration, the regenerated adsorbents were recycled 4 times in the recycle adsorption study. The experiments were performed at the same initial conditions.

\section{Results and discussion}

Characterization of adsorbent. In order to highlight the effect of $\mathrm{H}_{3} \mathrm{PO}_{4}$ in $\mathrm{HTC}$ process, the carbonized corncob prepared without adding $\mathrm{H}_{3} \mathrm{PO}_{4}$ was employed as a reference. The SEM images showed that the surface of corncob relative smooth with some flakes (Fig. 1a,b).

After hydrothermal reaction in the presence of phosphoric acid, the SEM images showed that the formation of a great deal of particles and aggregated dispersion on the surface (Fig. 1c). Detailed information on the structure was further obtained by enlarging SEM images. Figure 1d illustrated that the resulting particles are regularly distributed. These results revealed that adding $\mathrm{H}_{3} \mathrm{PO}_{4}$ could successfully increase the surface area, resulting in the increase of pore volume. Nitrogen adsorption/desorption isotherms in Fig. 2 were used to analyze structurally pores of the carbon samples. CA showed the surface area of $480 \mathrm{~m}^{2} / \mathrm{g}$.

The phases of the raw material and hydrothermal carbonized samples were observed by the XRD patterns. In comparison with the raw corncob, the characteristic peaks of the prepared CA became more obvious, indicating that single HTC process only depleted impurities but without destroying the "core" structure of corncob. As shown in Fig. 3c, the XRD pattern of the prepared CA exhibited one broad diffraction peaks $\left(2 \theta=15-25^{\circ}\right)$, indicating that the prepared CA existed in an amorphous carbon composed of aromatic carbon sheets form ${ }^{38}$. This result clearly suggests that the presence of phosphoric acid yields a carbonaceous structure composed of aromatic carbon sheets under HTC condition.

The adsorption efficiency of CA depends on the number and chemical reactivity of surface functional groups $^{39}$. The FT-IR technique was used to identify the characteristic functional groups. According to Fig. 3d, the FT-IR spectra of CA was obvious difference from that of the raw corncob, which imply that major spectral changes occurred in the presence of phosphoric acid after HTC process. The bands at 1,040 assigned to aromatic $\mathrm{C}-\mathrm{O}$ have nearly disappeared, while $\mathrm{C}=\mathrm{C}$ peak at $1,610 \mathrm{~cm}^{-1}$ and the $\mathrm{C}=\mathrm{O}$ peak at $1708 \mathrm{~cm}^{-1}$ were enhanced. All of these observations were in agreement with the structural characteristics of standard HTC process ${ }^{40}$, indicating that the presence of phosphoric acid promoted the carbonization of lignocellulosic biomass through HTC process at low temperature $\left(160^{\circ} \mathrm{C}\right)$ and introduced carboxyl group into the structure of the raw $\operatorname{corncob}^{41}$. These oxygen-containing functional groups can play a significant role in enhancing CA adsorption efficiency by means of specific adsorption such as $\mathrm{H}$-bonding and $\pi-\pi$ interaction $^{42}$.

Adsorption of MB. Effect of the initial pH. The $\mathrm{pH}$ is one of the most important parameter in the adsorption process, which regulates the adsorbents surface charge and influences the particles adsorption affinity in 

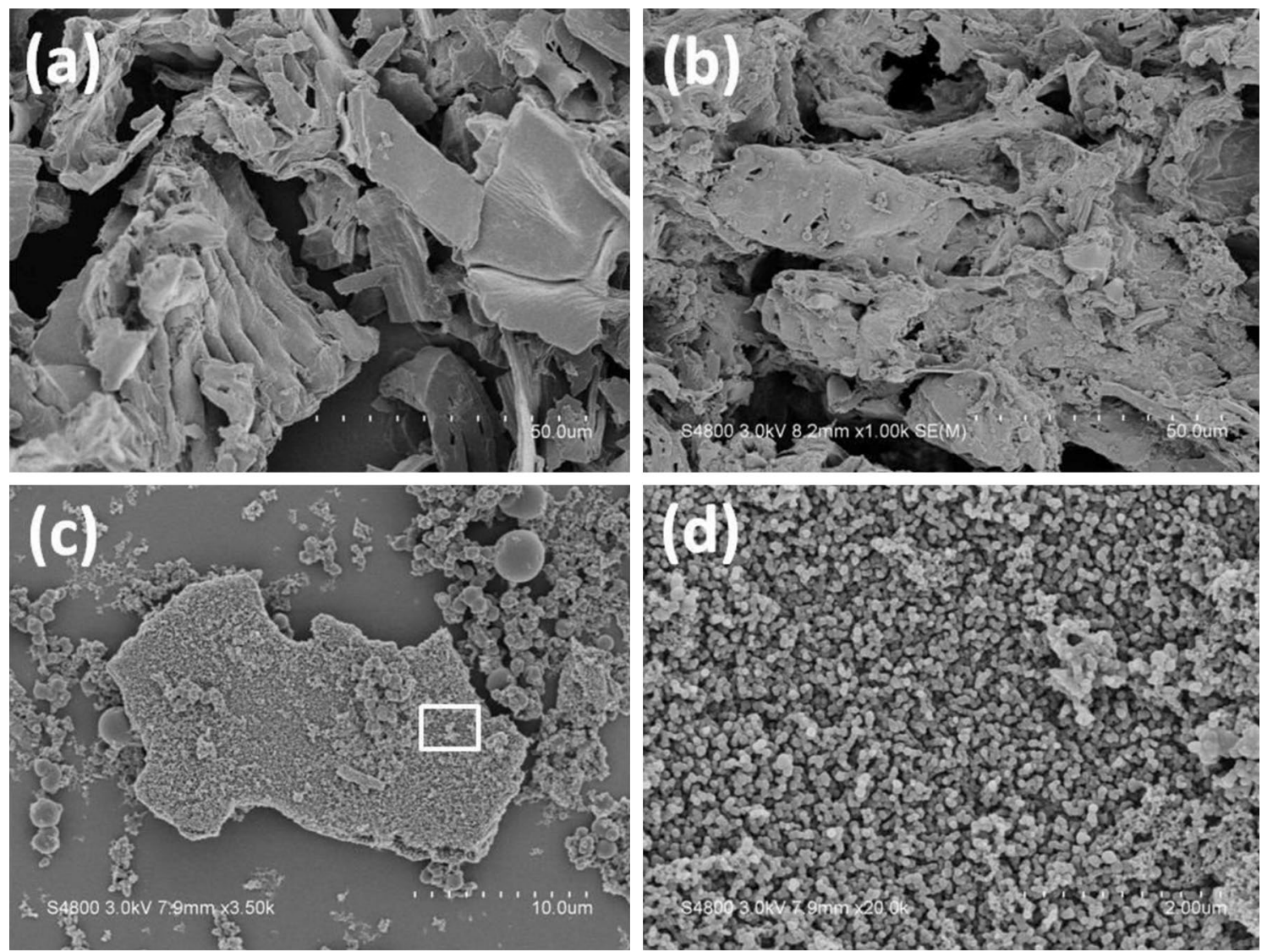

Figure 1. SEM images of corncob powder (a) before and (b) after hydrothermal carbonization at $160^{\circ} \mathrm{C}$ for $10 \mathrm{~h}$ without adding $\mathrm{H}_{3} \mathrm{PO}_{4}$, (c) after hydrothermal carbonization at $160{ }^{\circ} \mathrm{C}$ for $10 \mathrm{~h}$ adding $\mathrm{H}_{3} \mathrm{PO}_{4}$ and the enlarged view of the black frame of $\mathbf{c}(\mathbf{d})$.

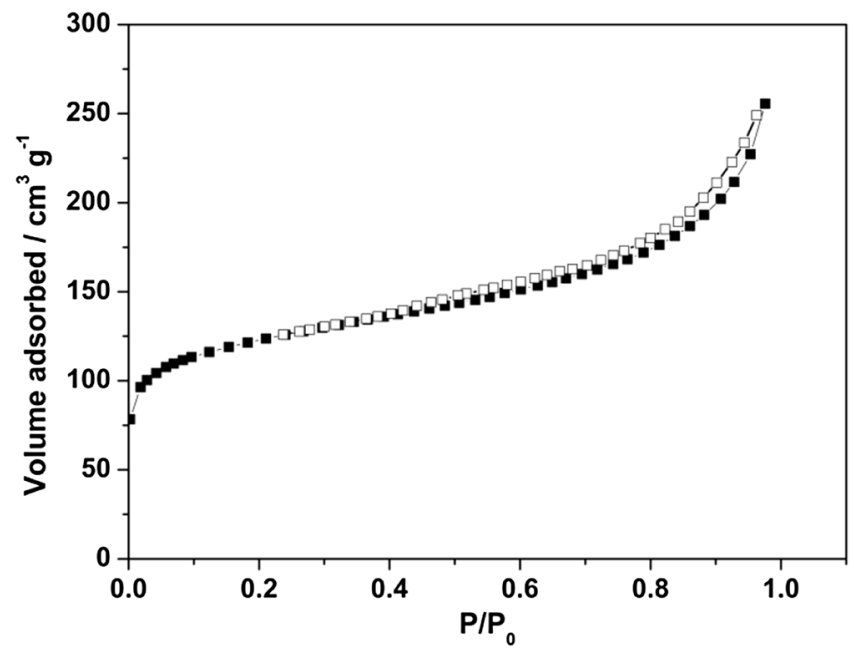

Figure 2. Nitrogen adsorption-desorption isotherms of carbonaceous adsorbent (CA).

various aqueous solutions ${ }^{43}$. In order to evaluate the influence of $\mathrm{pH}$ on adsorption of $\mathrm{MB}$, experiments were performed under the following condition: adsorbent dose $1.0 \mathrm{~g} / \mathrm{L}$, initial MB concentration $200 \mathrm{mg} / \mathrm{L}, \mathrm{pH}$ (from 2 to 12 ), reaction temperature $20 \pm 1{ }^{\circ} \mathrm{C}$ and contact time $120 \mathrm{~min}$. The removal ratio of $\mathrm{MB}$ increased with an increase of $\mathrm{pH}$ from 2 to 7 and thereafter slightly increased with increasing $\mathrm{pH}$ range from 7 to 12 , and the maximum removal was observed at $\mathrm{pH} 7$ (Fig. 4a). At very low $\mathrm{pH}$, lower adsorption efficiency was recorded due to the $\mathrm{H}^{+}$competed with $\mathrm{MB}$ molecules for the negative active sites on the adsorbent surface. Thus cationic dye $(\mathrm{MB})$ cannot move toward the positively charge surface area of adsorbent as a result of electrostatic repul- 

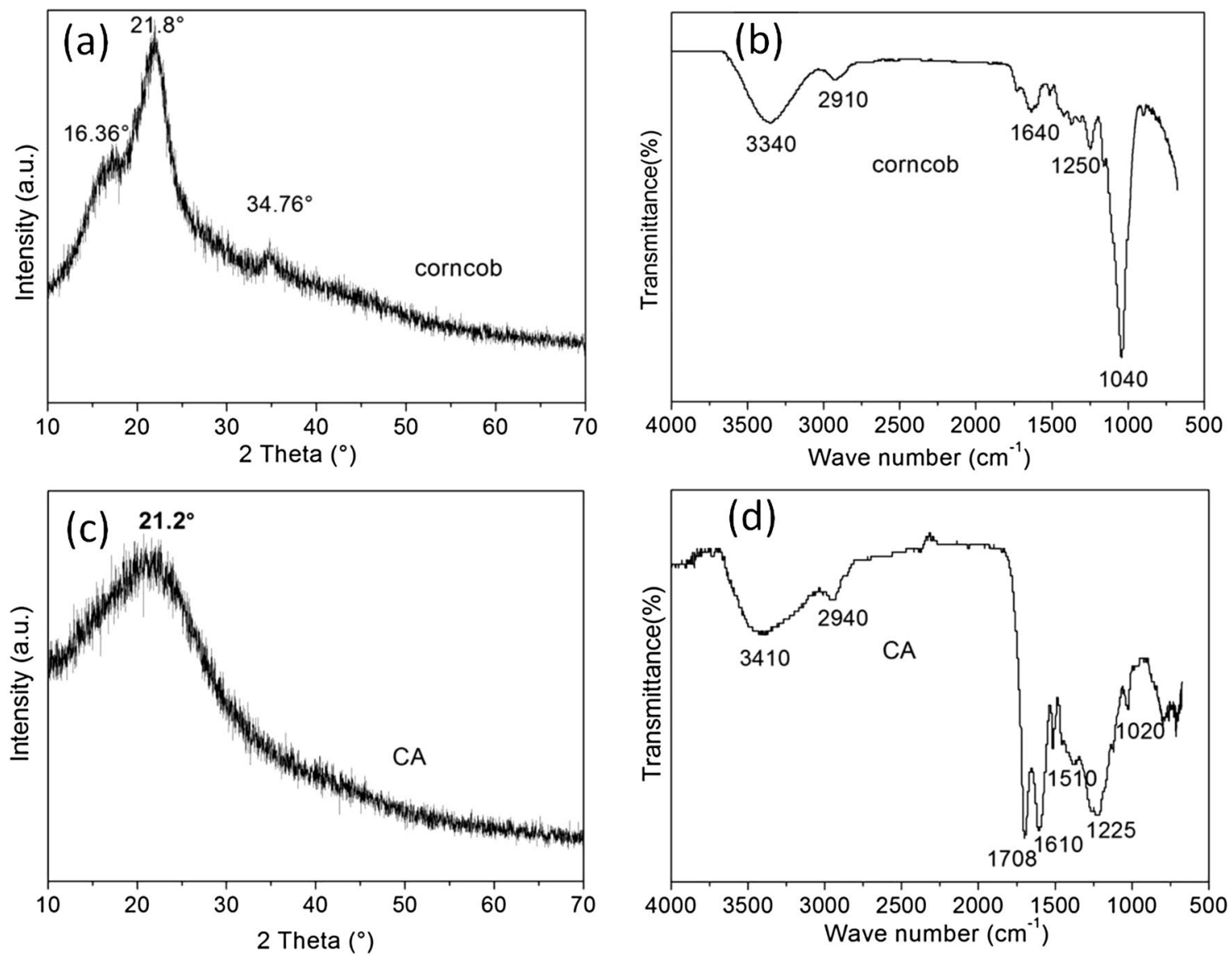

Figure 3. XRD pattern of corncob powder (a) and CA (c), FTIR spectra of corncob powder (b) and CA (d).
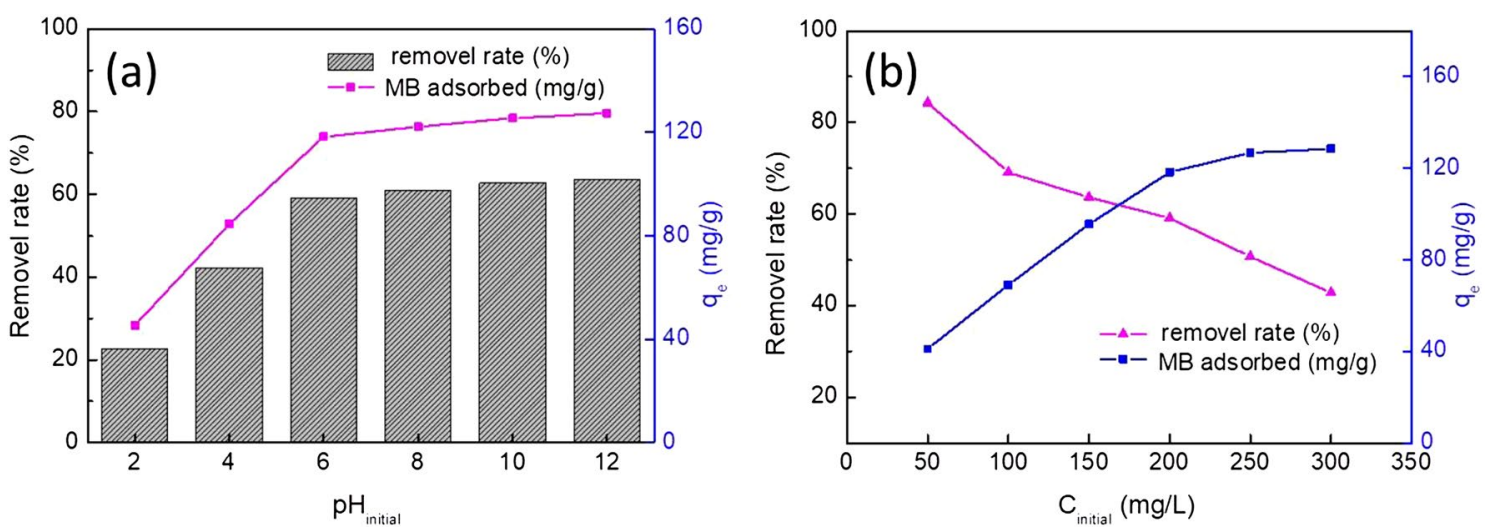

Figure 4. Effect of (a) $\mathrm{pH}$ and initial concentrations (b) for $\mathrm{MB}$ adsorbed on CA.

sive force and hence a lower removal was observed at low $\mathrm{pH}$ values ${ }^{44}$. At high $\mathrm{pH}$, a significant enhancement in adsorption was observed owing to electrostatic attraction increased between the adsorbent and cationic dye $(\mathrm{MB})^{26,45}$. Therefore, all further adsorption experiments were performed at $\mathrm{pH}$ values of 7 .

Effect of the initial MB concentrations. Adsorption behavior of cationic dye onto the adsorbent at various MB concentrations of $50-300 \mathrm{mg} / \mathrm{L}$ was also investigated as shown in Fig. $4 \mathrm{~b}$. The figure showed that the amount of $\mathrm{MB}$ adsorption adsorbed increased with increasing in the initial $\mathrm{MB}$ concentration, but the removal efficiency decreased from 81.28 to $42.81 \%$. The percentage of adsorption decreased may be explained that sorption sites on the surface area of adsorbent were insufficient to meet much more MB molecules available in aqueous solution $^{18,46}$. 

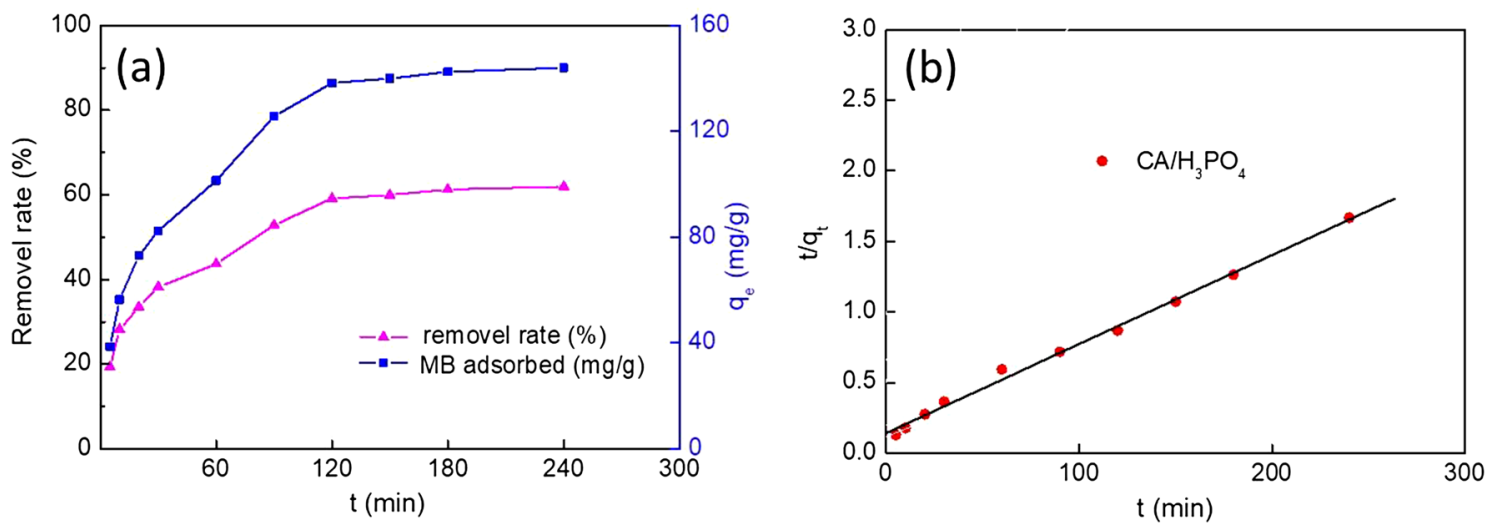

Figure 5. Effect of contact time on MB adsorbed on CA (a), and the pseudo second-order kinetic plots of MB adsorption on CA $(\mathbf{b})$.

Effect of the contact time. To evaluate the effect of contact time on the adsorption of MB molecules, the uptake capacity of the adsorbent with contact time was tested in Fig. 5a. It can be observed that removal efficiency was characterized by a rapid sorption phase followed by a slow phase as the contact time increases from 0 to $240 \mathrm{~min}$. The results revealed that an initial very fast step where $>80 \%$ of $\mathrm{MB}$ molecules were adsorbed within the first $120 \mathrm{~min}$ and a slow phase where equilibrium was attained within the later $120 \mathrm{~min}$, which might be attribute to that the availability of a large number of active sites on the surface of adsorbent at the initial stage were provided in aqueous solutions $\mathrm{s}^{2,47}$.

Adsorption isotherm. The adsorption isotherm studies are basic requirements for optimization of the adsorption systems, describing the relationship between $\mathrm{MB}$ molecules adsorbed onto the adsorbent and $\mathrm{MB}$ molecules in aqueous solution ${ }^{48}$. In current study, two types of well-known adsorption isotherms models Langmuir and Freundlich were fitted to analyze the adsorption equilibrium data ${ }^{16}$.

Langmuir isotherm model, which is valid for a monolayer adsorption with a homogeneous distribution of the adsorption sites and sorption energies, is mathematically given as follows ${ }^{49}$ :

$$
\frac{c_{e}}{q_{e}}=\frac{1}{K_{\mathrm{L}} q_{m}}+\frac{c_{e}}{q_{m}}
$$

where the values of $q_{\mathrm{e}}(\mathrm{mg} / \mathrm{g})$ and $c_{\mathrm{e}}(\mathrm{mg} / \mathrm{L})$ represent the sorption capacity at equilibrium and the equilibrium concentration, respectively; $K_{\mathrm{L}}(\mathrm{L} / \mathrm{mg})$ is the Langmuir isotherm equilibrium constant; $q_{\mathrm{m}}(\mathrm{mg} / \mathrm{g})$ is the maximum sorption capacity.

Freundlich isotherm model is derived by assuming that the MB molecules can be applied for multilayer sorption. It is used to describe heterogeneous systems by the following equation ${ }^{50}$ :

$$
\ln q_{e}=\ln K_{\mathrm{f}}+\frac{1}{n} \ln c_{\mathrm{e}}
$$

where the values of $q_{\mathrm{e}}(\mathrm{mg} / \mathrm{g})$ and $c_{\mathrm{e}}(\mathrm{mg} / \mathrm{L})$ represent the sorption capacity at equilibrium and the equilibrium concentration, respectively; $K_{\mathrm{f}}(\mathrm{mg} / \mathrm{g})$ is the Freundlich isotherm constant; indicating the adsorption capacity related to bond strength; $1 / \mathrm{n}$ is also Freundlich isotherm constant that stand for adsorption intensity.

The adsorption isotherms of $\mathrm{MB}$ molecules onto the adsorbent were shown in Fig. 6. The Langmuir and Freundlich isotherms parameters of corncob and CA were given in Table 1. The results show that the value of $R^{2}$ for Langmuir isotherm model (0.993 for CA) was higher than that of Freundlich isotherm model ( 0.938 for $\mathrm{CA}$ ), indicating that Langmuir isotherm model was better fitted to describe the adsorption of MB molecules onto CA. In addition, the calculated maximum sorption capacity of MB by Langmuir model was $140.25 \mathrm{mg} / \mathrm{g}$ in Fig. 6a, which was quite close to their corresponding experimental data $(128.43 \mathrm{mg} / \mathrm{g})$. These results suggest that the monolayer adsorption occur on the surface of the CA for cationic dye $\mathrm{e}^{31}$.

Adsorption kinetics. Adsorption kinetic study is important to provide the vital information about the mechanism of adsorption process and the reaction pathways in the treatment of waste water. Thus, to investigate the adsorption kinetics, three types of well-known kinetic models were studied: pseudo-first-order kinetic model, pseudo-second-order kinetic model and intra-particle diffusion model. The three models were expressed as follows ${ }^{51}$ :

$$
\begin{gathered}
\text { Pseudo-first-order kinetic equation: } \ln \left(q_{e}-q_{t}\right)=\ln q_{e}-k_{1} t \\
\text { Pseudo-second-order kinetic equation: } \frac{t}{q_{t}}=\frac{1}{k_{2} q_{e}^{2}}+\frac{t}{q_{e}}
\end{gathered}
$$



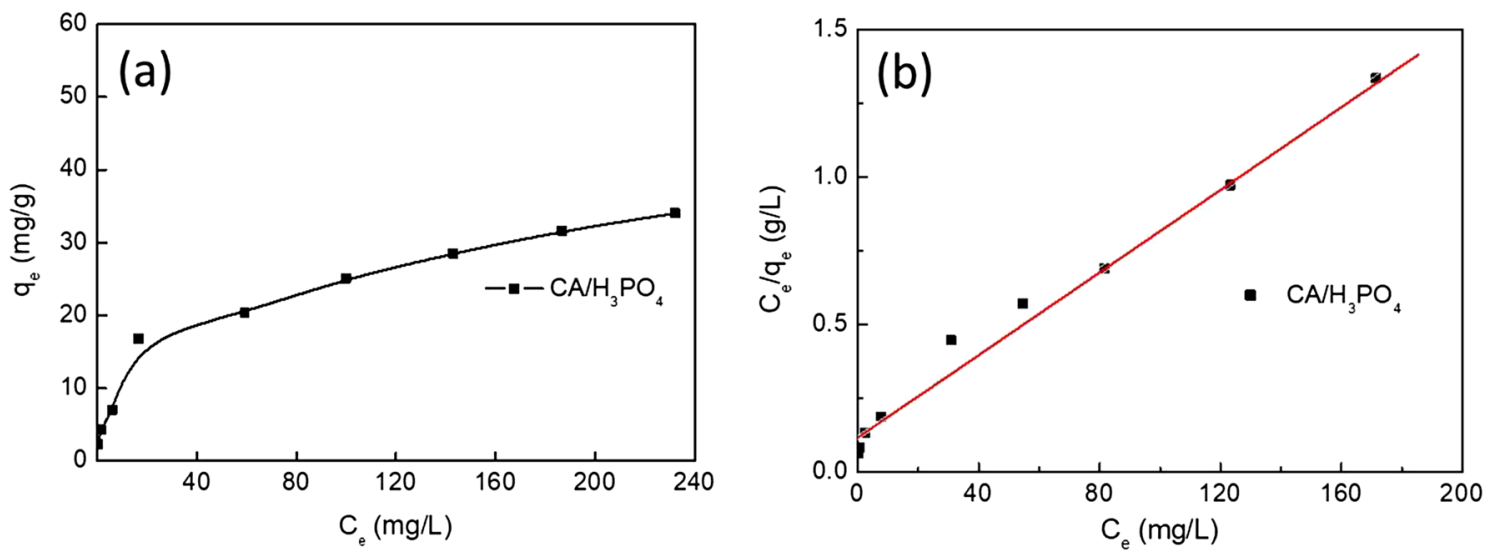

Figure 6. Adsorption isotherms for MB on CA (a), and the Langmuir isotherm plots for adsorption of MB on CA (b).

\begin{tabular}{|l|l|l|}
\hline Isothermal models & Parameters & CA \\
\hline \multirow{4}{*}{ Langmuir } & $K_{\mathrm{L}}(\mathrm{L} / \mathrm{mg})$ & 0.5795 \\
\cline { 2 - 3 } & $q_{\mathrm{m}}(\mathrm{mg} / \mathrm{g})$ & 140.25 \\
\cline { 2 - 3 } & $R^{2}$ & 0.993 \\
\hline \multirow{3}{*}{ Freundlich } & $K_{\mathrm{F}}\left(\mathrm{mg} / \mathrm{g}(1 / \mathrm{mg})^{1 / \mathrm{n}}\right)$ & 87.102 \\
\cline { 2 - 3 } & $n$ & 5.1524 \\
\cline { 2 - 3 } & $R^{2}$ & 0.938 \\
\hline
\end{tabular}

Table 1. Isotherms parameters of $\mathrm{MB}$ on $\mathrm{CA}$.

\begin{tabular}{|l|l|l|}
\hline Kinetic models & Parameters & CA \\
\hline \multirow{4}{*}{ Pseudo-first-kinetic models } & $q_{\mathrm{e}}(\mathrm{mg} / \mathrm{g})$ & 103.94 \\
\cline { 2 - 3 } & $K_{1}(1 / \mathrm{min})$ & 0.02559 \\
\cline { 2 - 3 } & $R^{2}$ & 0.989 \\
\hline \multirow{4}{*}{ Pseudo-second-kinetic models } & $K_{2}(\mathrm{~g} /(\mathrm{mg} \mathrm{min})$ & 0.0002206 \\
\cline { 2 - 3 } & $h(\mathrm{mg} /(\mathrm{g} \mathrm{min}))$ & 40.44 \\
\cline { 2 - 3 } & $R^{2}$ & 0.996 \\
\hline \multirow{3}{*}{ Intra-particle diffusion equation } & $K_{3}\left(\mathrm{mg} \mathrm{g}^{-1} \mathrm{~min}^{-1 / 2}\right)$ & 5.9978 \\
\cline { 2 - 3 } & $C$ & 24.2520 \\
\cline { 2 - 3 } & $R^{2}$ & 0.966 \\
\hline
\end{tabular}

Table 2. Kinetic constants of $\mathrm{MB}$ on $\mathrm{CA}$.

Intra-particle diffusion model: $q_{t}=k_{i} t^{\frac{1}{2}}+C$

where the values of $q_{\mathrm{e}}(\mathrm{mg} / \mathrm{g})$ and $q_{\mathrm{t}}(\mathrm{mg} / \mathrm{g})$ are the amounts of $\mathrm{MB}$ absorbed at equilibrium and at time $t(\mathrm{~min})$; $k_{1}(1 / \mathrm{min})$ and $k_{2}(\mathrm{~g} /(\mathrm{mg} \mathrm{min}))$ are the equilibrium rate constant of pseudo-first-order adsorption and the equilibrium rate constant of pseudo-second-order adsorption, respectively. $k_{\mathrm{i}}\left(\mathrm{mg} /\left(\mathrm{g} \mathrm{min}^{1 / 2}\right)\right)$ is the intra-particle diffusion rate constant; $\mathrm{C}(\mathrm{mg} / \mathrm{g})$ is a constant.

Three types of kinetic models for MB molecules onto adsorbent were investigated. The calculated relevant parameters of the three kinetic equations for the adsorption of $\mathrm{MB}$ molecules onto adsorbent were shown in Table 2. Comparison of the correlation coefficient $\left(R^{2}\right)$ values for three models suggested that the pseudo-secondorder model was better fitted to describe the adsorption process due to its highest values. However, the value of the correlation coefficient $\left(R^{2}<0.98\right)$ of intra-particle diffusion model demonstrated that this model was not feasible to describe the adsorption process owing to a weak correlation. Moreover, Fig. $4 \mathrm{~b}$ showed that the experimental data fitted the theoretic pseudo-second-order model simulated curves fairly well. These results indicated that chemical adsorption might be the rate-limiting step that controls the adsorption MB onto adsorbent, which were consistent with the previous studies reported in literatures ${ }^{52}$. 


\begin{tabular}{|l|l|l|l|}
\hline Adsorbent & Qm $(\mathbf{m g} / \mathbf{g})$ & Preparing temperature $\left({ }^{\circ} \mathbf{C}\right)$ & Reference \\
\hline Phosphoric acid treated corncob & 140.25 & 160 & This study \\
\hline Acetic acid treated rice bran & 25.1 & 90 & 25 \\
\hline Waste apricot-based activated carbon & 102.04 & 500 & 53 \\
\hline Sulfuric acid treated Parthenium & 88.29 & 300 & 54 \\
\hline Zinc chloride treated Stipa tenacissima & 178.44 & 600 & 55 \\
\hline Sodium hydroxide treated corn stalk & 49.01 & 75 & 56 \\
\hline Tartaric acid treated bagasse & 57.14 & 120 & 57 \\
\hline Surfactant-modified pineapple leaf powder & 52.6 & 90 & 58 \\
\hline
\end{tabular}

Table 3. Comparison of adsorption capacities of other biomass-derived adsorbents for removal of MB.

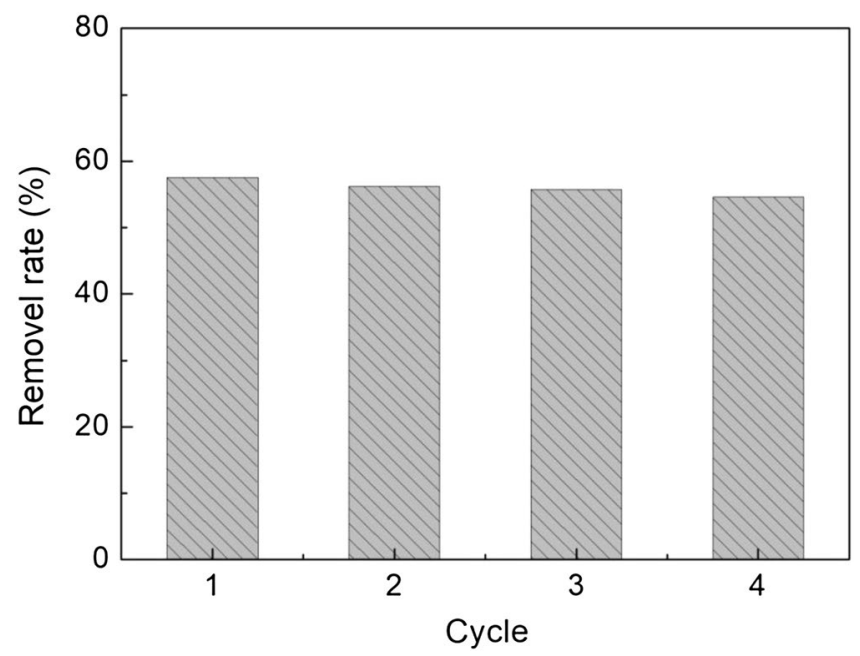

Figure 7. The removal rate of $\mathrm{MB}$ was employed to evaluate their operational stability.

Comparison with other adsorbents. Comparisons of the maximum adsorption capacity (Qmax value) of CA with other biomass-derived adsorbents are presented in Table $3^{25,53-58}$. The CA shows the comparable adsorption capacity for $\mathrm{MB}$ compared to other biomass-derived adsorbents. And given its adsorption capacity and preparation at low temperature, CA was promising for $\mathrm{MB}$ removal from the waste water.

Desorption studies. The reusability of the adsorbent is also very important for its potential commercial application and economic feasibility in wastewater treatment. The tests of MB desorption were carried out with four times repeated batch adsorption-desorption cycles as shown in Fig. 7. It can be observed that CA still retained satisfactory adsorption efficiency of $\mathrm{MB}$ molecules even after four cycles of reuses, indicating the good reusability of CA.

\section{Conclusions}

In this work, an effective modification method based corncob with phosphoric acid through HTC at low temperature conditions is described. As we know, this is the first report of the synthesis of carbonaceous adsorbent from lignocellulosic biomass by using a low-temperature hydrothermal method. A large number of oxygencontaining groups and pore channels were introduced, resulting in a significantly enhance in the as-obtained adsorbent adsorption capability. The synthesized carbonaceous adsorbent may be used for organic pollutants removal from water treatment at large scale economically.

Received: 22 November 2019; Accepted: 19 June 2020

Published online: 27 July 2020

\section{References}

1. Spagnoli, A. A., Giannakoudakis, D. A. \& Bashkova, S. Adsorption of methylene blue on cashew nut shell based carbons activated with zinc chloride: The role of surface and structural parameters. J. Mol. Liq. 229, 465-471 (2017).

2. Ali, I., Alothman, Z. A. \& Alharbi, O. M. L. Supra molecular mechanism of the removal of 17- $\beta$-estradiol endocrine disturbing pollutant from water on functionalized iron nano particles. J. Mol. Liq. 441, 123-129 (2017).

3. Ali, I. et al. Artificial neural network modelling of amido black dye sorption on iron composite nano material: Kinetics and thermodynamics studies. J. Mol. Liq. 250, 1-8 (2018). 
4. Ali, I. New generation nano-adsorbents for the removal of emerging contaminants in water. J. Mol. Liq. 261, 583-593 (2018).

5. Alharbi, O. M. L. et al. Health and environmental effects of persistent organic pollutants. J. Mol. Liq. 263, 442-453 (2018).

6. Burakova, E. A. et al. Novel and economic method of carbon nanotubes synthesis on a nickel magnesium oxide catalyst using microwave radiation. J. Mol. Liq. 253, 340-346 (2018).

7. Basheer, A. A. \& Ali, I. Stereoselective uptake and degradation of $( \pm)-o, p-D D D$ pesticide stereomers in water sediment system. Chirality 30, 1088-1095 (2018).

8. Basheer, A. A. Chemical chiral pollution: Impact on the society and science and need of the regulations in the 21 st century. Chirality 30, 402-406 (2018).

9. Popa, N. \& Visa, M. The synthesis, activation and characterization of charcoal powder for the removal of methylene blue and cadmium from wastewater. Adv. Powder Technol. 28, 1866-1876 (2017).

10. Ali, I. Microwave assisted economic synthesis of multi walled carbon nanotubes for arsenic species removal in water, batch and column operations. J. Mol. Liq 271, 677-685 (2018).

11. Ali, I. et al. Water treatment by new generation graphene materials. Hope for Bright Future. Environ. Sci. Pollut. Res 25, 7315-7329 (2018).

12. Ali, I. et al. Modeling of fenuron pesticide adsorption on CNTs for mechanistic insight and removal in water. Environ. Res. 170, 389-397 (2019).

13. Ali, I. et al. Graphene based adsorbents for remediation of noxious pollutants from wastewater. Environ. Int. 127, 160-180 (2019).

14. Ali, I. et al. Water treatment by new-generation graphene materials: Hope for bright future. Environ. Sci. Pollut. Res. 25, 7315-7329 (2018).

15. Ali, I. et al. Facile and eco-friendly synthesis of functionalized iron nanoparticles for cyanazine removal in water. Colloids Surf. $B$ 171, 606-613 (2018).

16. Shakoor, S. \& Nasar, A. Removal of methylene blue dye from artificially contaminated water using citrus limetta peel waste as a very low cost adsorbent. J. Taiwan Inst. Chem. E 66, 154-163 (2016).

17. Chen, L. et al. Removal of methylene blue from water by cellulose/grapheme oxide fibres. J. Exp. Nanosci. 11, 1156-1170 (2016).

18. Tamilselvi, S., Asaithambi, M. \& Sivakumar, V. An eco-friendly non-conventional adsorbent from silk cotton fiber for the removal of methylene blue dye, Indian. J. Chem. Technol. 23, 497-505 (2016).

19. Ali, I. et al. Preparation of a carboxymethylcellulose-iron composite for uptake of atorvastatin in water. Int. J. Biol. Macromol. 132, 244-253 (2019).

20. Al-Shaalan, N. H. et al. High performance removal and simulation studies of diuron pesticide in water on MWCNTs. J. Mol. Liq. 289, 111039 (2019).

21. Ali, I. et al. Removal of copper(II) and zinc(II) ions in water on a newly synthesized polyhydroquinone/graphene nanocomposite material: Kinetics, thermodynamics and mechanism. ChemistrySelect 4, 12708-12718 (2019).

22. Kallel, F. et al. Sorption and desorption characteristics for the removal of a toxic dye, methylene blue from aqueous solution by a low cost agricultural by-product. J. Mol. Liq. 219, 279-288 (2016).

23. Bharathi, K. S. \& Ramesh, S. T. Removal of dyes using agricultural waste as low-cost adsorbents: A review. Appl. Water Sci. 3 , 773-790 (2013).

24. Oyelude, E. O. \& Owusu, U. R. Adsorption of methylene blue from aqueous solution using acid modified Calotropis procera leaf powder. J. Appl. Sci. Environ. Sanitation 6, 477-484 (2011).

25. Yao, S., Lai, H. \& Shi, Z. Adsorption of methylene blue from aqueous solution using acetic acid modified rice bran. J. Indian Chem. Soc. 90, 629-635 (2013).

26. Liu, X. et al. Characterization of corncob-derived biochar and pyrolysis kinetics in comparison with corn stalk and sawdust. Bioresour. Technol. 170, 76-82 (2014).

27. Ma, H. et al. Novel synthesis of a versatile magnetic adsorbent derived from corncob for dye removal. Bioresour. Technol. 190, 13-20 (2017).

28. Huang, Y. X. \& Keller, A. A. Magnetic nanoparticle adsorbents for emerging organic contaminants. ACS Sustain. Chem. Eng. 1, 731-736 (2013).

29. Mohan, D. et al. Organic and inorganic contaminants removal from water with biochar, a renewable, low cost and sustainable adsorbent-a critical review. Bioresour. Technol. 160, 191-202 (2014).

30. Rajapaksha, A. U. et al. Engineered/designer biochar for contaminant removal/immobilization from soil and water: Potential and implication of biochar modifica-tion. Chemosphere 148, 276-291 (2016).

31. Cho, H. H. et al. Sorption of aqueous $\mathrm{Zn}[\mathrm{II}]$ and $\mathrm{Cd}[\mathrm{II}]$ by multiwall carbon nanotubes: The relative roles of oxygen-containing functional groups and graphenic carbon. Langmuir 26, 967-981 (2010).

32. Uchimiya, M., Chang, S. \& Klasson, K. T. Screening biochars for heavy metal retention in soil: Role of oxygen functional groups. J. Hazard Mater. 190, 432-441 (2011).

33. Fang, Q. et al. Aromatic and hydrophobic surfaces of wood-derived biochar enhance perchlorate adsorption via hydrogen bonding to oxygen-containing organic groups. Environ. Sci. Technol. 48, 279-288 (2014).

34. Abdel Hakim, A. A., Nassar, M. \& Emam, A. Preparation and characterization of rigid polyurethane foam prepared from sugarcane bagasse polyol. Mater. Chem. Phys. 129, 301-307 (2011).

35. Ge, M. L. et al. A maleic anhydride grafted sugarcane bagasse adsorbent and its performance on the removal of methylene blue from related wastewater. Mater. Chem. Phys. 192, 147-155 (2017).

36. Xu, Y. et al. Enhanced adsorption of methylene blue by citric acid modification of biochar derived from water hyacinth (Eichornia crassipes). Environ. Sci. Pollut. Res. Int. 23, 23606-23618 (2016).

37. Zhen, M. et al. Decontamination of methylene blue from aqueous solution by rhamnolipid-modified biochar. BioResources 13, 3061-3081 (2018).

38. Liu, W. J. et al. Facile synthesis of highly efficient and recyclable magnetic solid acid from biomass waste. Sci. Rep. 3, 2419-2424 (2013).

39. Ren, C. R. et al. Highly efficient adsorption of heavy metals onto novel magnetic porous composites modified with amino groups. J. Chem. Eng. Data 62, 1865-1875 (2017).

40. Fechler, N. et al. Salt and sugar: Direct synthesis of high surface area carbon materials at low temperatures via hydrothermal carbonization of glucose under hypersaline conditions. J. Math. Chem. A 1, 9418-9421 (2013).

41. Calucci, L., Rasse, D. P. \& Forte, C. Solid-state nuclear magnetic resonance characterization of chars obtained from hydrothermal carbonization of corncob and miscanthus. Energy Fuels 27, 303-309 (2013).

42. Ma, H. J. Hydrothermal preparation and characterization of novel corncob-derived solid acid catalysts. J. Agric. Food Chem. 62, 5345-5353 (2014).

43. Foo, K. Y. \& Hameed, B. H. Potential of jackfruit peel as precursor for activated carbon prepared by microwave induced $\mathrm{NaOH}$ activation. Bioresour. Technol. 112, 143-150 (2012).

44. Zhou, X. P. \& Xie, X. L. Study on PP/PMMA grafted sisal fiber composited(II) effect of surface treatment on the structure and properties of sisal fiber-reinforced polypropylene composites. J. Polym. Mater. Sci. Eng. 20, 138-141 (2004).

45. Bhatti, H. N., Akhtar, N. \& Saleem, N. Adsorptive removal of methylene blue by low-cost citrus Sinensis bagasse: Equilibrium, kinetic and thermodynamic characterization. Arab. J. Sci. Eng. 37, 9-18 (2012). 
46. Wang, Y. X. et al. Cellulose-based porous adsorbents with high capacity for methylene blue adsorption from aqueous solutions. Fiber Polym. 18, 891-899 (2017).

47. Sharmeen Afroze, S. et al. Adsorption performance of continuous fixed bed column for the removal of methylene blue (MB) dye using Eucalyptus sheathiana bark biomass. Res. Chem. Intermed 42, 2343-2364 (2016).

48. Kamaru, A. A. et al. Raw and surfactant-modified pineapple leaf as adsorbent for removal of methylene blue and methyl orange from aqueous solution. Desalin. Water Treat. 57, 18836-18850 (2016).

49. Langmuir, I. The adsorption of gases on plane surfaces of glass, mica and platinum. J. Am. Chem. Soc. 40, 1361 (1918).

50. Freundlich, H. M. F. Over the adsorption in solution. J. Phys. Chem. 57, 385 (1906).

51. Kumar, R., Sharma, R. K. \& Singh, A. P. Cellulose based grafted biosorbents-Journey from lignocellulose biomass to toxic metal ions sorption applications-A review. J. Mol. Liq. 232, 62-93 (2017).

52. Hameed, B. H., Krishni, R. R. \& Sata, S. A. A novel agricultural waste adsorbent for the removal of cationic dye from aqueous solutions. J. Hazard Mater. 162, 305-311 (2009).

53. Basar, C. A. Applicability of the various adsorption models of three dyes adsorption onto activated carbon prepared waste apricot. J. Hazard Mater. 135, 232-241 (2006).

54. Lata, H., Grag, V. K. \& Gupta, R. K. Removal of a basic dye from aqueous solution by adsorption using Parthenium hysterophorus: An agricultural waste. Dyes Pigm. 74, 653-658 (2007).

55. Bouguettouchaa, A. D. et al. Novel activated carbon prepared from an agricultural waste, Stipa tenacissima, based on $\mathrm{ZnCl}_{2}$ activation-characterization and application to the removal of methylene blue. Desalin. Water Treat. 57, 24056-24069 (2016).

56. Ma, D. Z. et al. Fabrication of the novel hydrogel based on waste corn stalk for removal of methylene blue dye from aqueous solution. Appl. Surf. Sci. 422, 944-952 (2017).

57. Low, L. W. et al. Studies on the adsorption omethylene blue dye from aqueous solution onto low-cost tartaric acid treated Bagasse. Apcbee Procedia 1, 103-109 (2012).

58. Kamaru, A.A. et al. Raw and surfactant-modified pineapple leaf as adsorbent for removal of methylene blue and methyl orange from aqueous solution. Desalin. Water Treat. 59, 18836-18850 (2016).

\section{Acknowledgements}

The authors gratefully acknowledge the financial support by the National Natural Science Foundation of China (Grant Nos. 21673002, 31371285), Provincial university student innovation project (Grant No. XJDC2019235) and National University Students Innovation Project of China (Grant No. 201510364011).

\section{Author contributions}

Y.W. and P.C. designed experiments; Y.W., Y.Z. and G.J. carried out experiments; Y.W. and P.C. analyzed experimental results. Y.W. and P.C. wrote the manuscript. P.C. and Z.C. supervised the project.

\section{Competing interests}

The authors declare no competing interests.

\section{Additional information}

Correspondence and requests for materials should be addressed to P.C. or Z.C.

Reprints and permissions information is available at www.nature.com/reprints.

Publisher's note Springer Nature remains neutral with regard to jurisdictional claims in published maps and institutional affiliations.

(c) Open Access This article is licensed under a Creative Commons Attribution 4.0 International

License, which permits use, sharing, adaptation, distribution and reproduction in any medium or format, as long as you give appropriate credit to the original author(s) and the source, provide a link to the Creative Commons license, and indicate if changes were made. The images or other third party material in this article are included in the article's Creative Commons license, unless indicated otherwise in a credit line to the material. If material is not included in the article's Creative Commons license and your intended use is not permitted by statutory regulation or exceeds the permitted use, you will need to obtain permission directly from the copyright holder. To view a copy of this license, visit http://creativecommons.org/licenses/by/4.0/.

(c) The Author(s) 2020 